\title{
Ethnic diversity in Science
}

\section{Why we need ethnic diversity in science}

Does the UK's structural racism harm UK science? The answer to this question is yes. For example, individuals of Black African and Pakistani heritage are three times more likely to die from COVID-19 in the $\mathrm{UK}^{1}$. This has been attributed to longstanding racial inequities which mean that Black, Asian and minority ethnic individuals (ethnic minorities) are more likely to be in occupations with a high risk of contracting COVID-19 and/or live in crowded conditions with a high risk of transmitting COVID19. It is unfortunate that the risks to certain populations, from the pandemic, were not known prior to these deaths being recorded. However, as funded university researchers in the UK are not diverse, this is not surprising, since researchers follow their interests when developing their ideas. MRC grant success rates were lower in 2017/ 2018 for applicants who ticked the "other" ethnicity box when asked to declare their ethnicity (Table 1$)^{2}$ and EPSRC funding rates are lower for ethnic minority applicants $(\text { Table } 2)^{3}$.

There is growing evidence that ethnic diversity at all levels of decision making leads to better quality outcomes. Academic papers arising from international collaborations ${ }^{4}$ or with ethnically mixed authors ${ }^{5}$ are more likely to be cited. After analysing 9 million publications, AlShebli et al concluded that, "ethnic diversity is the strongest predictor of a field's scientific impact". In the private sector, McKinsey's latest edition (2020) of the report, Diversity Wins - Why Inclusion Matters, found, after analyses of 1000 companies in 15 countries, that those in the top quartile for ethnic diversity in their executive teams were $35 \%$ more likely to be profitable and those in the top quartile for gender diversity in their executive teams were $25 \%$ more likely to be profitable ${ }^{6}$. The report concluded that, "there continues to be a higher likelihood of outperformance difference with ethnicity than with gender" ${ }^{\prime \prime}$. Similar conclusions were drawn by Mckinsey in 2014 and 2017 and one of the reasons could be that companies led by ethnically diverse management teams tend to introduce more innovative products ${ }^{7}$. Ethnic diversity in stock pricing led to stocks being $58 \%$ more accurately priced when compared to pricing by ethnically homogenous teams ${ }^{8}$. Finally, ethnically diverse juries relied more on the evidence when making a decision? . 
A further driver supporting diversity in scientific research is that the UK is a multicultural society with ethnic minorities making up $13 \%$ of the UK population ${ }^{10}$. Additionally, the UK is home to a number of top global universities and as UK research is consumed around the world, there is a real need to reflect the needs of global populations. UK researchers already punch above their weight by forging global collaborations ${ }^{4}$. Increasing the diversity in UK science will only enhance this impact.

Table 1: Medical Research Council grant application success rates by ethnicity in 2017/2018

\begin{tabular}{|l|l|l|l|l|l|}
\hline Ethnicity & \multicolumn{2}{|l|}{$\begin{array}{l}\text { No. } \\
\text { applications }\end{array}$} & \multicolumn{2}{|l|}{$\begin{array}{l}\text { No. } \\
\text { applications }\end{array}$} & $\begin{array}{l}\text { Success } \\
\text { awarded }\end{array}$ \\
\hline White & 1,233 & $80 \%$ & 311 & $83 \%$ & $25 \%$ \\
\hline Unknown & 86 & $6 \%$ & 16 & $4 \%$ & $19 \%$ \\
\hline Other & \\
\hline
\end{tabular}

aThere is an assumption that "other" refers to Black, Asian and ethnic minority

Table 2: Engineering and Physical Sciences Research Council (EPSRC) funding rates by ethnicity

\begin{tabular}{|l|l|l|}
\hline Ethnicity & \% of Applicants applying for EPSRC awards & \% of EPSRC awards \\
\hline White & 72.1 & 80.7 \\
\hline Mixed & 2.3 & 1.4 \\
\hline Asian & 7.9 & 5.6 \\
\hline Black & 1.7 & 0.4 \\
\hline Chinese & 7.1 & 5.2 \\
\hline
\end{tabular}

\section{Why is UK science not diverse?}

Considering the benefits outlined above, why then is UK science not diverse? There are structural inequalities in the UK that prevent ethnic minorities from achieving scientific careers and these inequalities are evidenced by the impacts outlined below. 
Table 3: Key Stage 1 Achievements $^{b}$ by ethnicity in England $2012-2019^{11}$

\begin{tabular}{|l|l|l|l|l|l|l|l|l|}
\hline \multirow{5}{*}{} & \multicolumn{9}{|l}{ \% Achieving the standard in each ethnic group } \\
\cline { 2 - 10 } & Reading & Reading & Science & Science & & & Writing & Writing \\
& $\mathbf{2 0 1 2}-$ & $\mathbf{( 2 0 1 6}-$ & $\mathbf{( 2 0 1 2 -}$ & $\mathbf{( 2 0 1 6}-$ & Mathematics & Mathematics & $\mathbf{( 2 0 1 2}-$ & $\mathbf{( 2 0 1 6}-$ \\
Ethnicity & $\mathbf{2 0 1 5 )}$ & $\mathbf{2 0 1 9 )}$ & $\mathbf{2 0 1 5 )}$ & $\mathbf{2 0 1 9 )}$ & $\mathbf{( 2 0 1 2 - \mathbf { 2 0 1 5 } )}$ & $\mathbf{( 2 0 1 6 - \mathbf { 2 0 1 9 } )}$ & $\mathbf{2 0 1 5 )}$ & $\mathbf{2 0 1 9 )}$ \\
\hline White & $89 \pm 1.7$ & $75 \pm 1$ & $91 \pm 0.8$ & $83 \pm 0$ & $92 \pm 0.8$ & $75 \pm 1.5$ & $86 \pm 2.1$ & $67 \pm 2.1$ \\
\hline Mixed & $90 \pm 1.4$ & $77 \pm 1$ & $91 \pm 0.8$ & $84 \pm 0.6$ & $92 \pm 0.8$ & $76 \pm 1.5$ & $86 \pm 1.7$ & $70 \pm 2$ \\
\hline Asian & $90 \pm 1.4$ & $77 \pm 1$ & $88 \pm 1.7$ & $81 \pm 1$ & $92 \pm 1.3$ & $77 \pm 1.5$ & $87 \pm 2.2$ & $72 \pm 2.5$ \\
\hline Black & $89 \pm 1.7$ & $77 \pm 0.6$ & $88 \pm 1.6$ & $80 \pm 0.6$ & $90 \pm 1.7$ & $73 \pm 1.5$ & $86 \pm 2.7$ & $71 \pm 1.6$ \\
\hline Chinese & $91 \pm 1.2$ & $83 \pm 2.3$ & $91 \pm 0.5$ & $88 \pm 1.5$ & $96 \pm 0.5$ & $90 \pm 1.7$ & $89 \pm 1.7$ & $81 \pm 3.2$ \\
\hline
\end{tabular}

${ }^{b}$ assessments changed in 2016

Table 4: Key Stage 2 Achievements $^{c}$ by ethnicity in England ${ }^{12}$

\begin{tabular}{|l|l|l|}
\hline \multirow{2}{*}{ Ethnicity } & \multicolumn{2}{|l|}{ \% Achieving the standard in each ethnic group } \\
\cline { 2 - 3 } & $\begin{array}{l}\text { Reading, Writing and Mathematics } \\
\mathbf{( 2 0 1 1}-\mathbf{2 0 1 5 )}\end{array}$ & $\begin{array}{l}\text { Reading, Writing and Mathematics } \\
\mathbf{( 2 0 1 6}-\mathbf{2 0 1 9 )}\end{array}$ \\
\hline White & $75 \pm 5.1$ & $61 \pm 5.2$ \\
\hline Mixed & $76 \pm 5.1$ & $63 \pm 4.8$ \\
\hline Asian & $76 \pm 5.1$ & $64 \pm 6.4$ \\
\hline Black & $72 \pm 6.4$ & $60 \pm 6.0$ \\
\hline Chinese & $85 \pm 3.3$ & $77 \pm 4.5$ \\
\hline
\end{tabular}

a assessments changed in 2016

Table 5: Achieving at least 3 A grades at A Level by ethnicity $(2017-2018)^{13}$

\begin{tabular}{|l|r|}
\hline Ethnicity & \% Achieving at least 3 A grades at A level (2017 - 2018) \\
\hline White & 11 \\
\hline Mixed & 11.2 \\
\hline Asian & 11 \\
\hline Black & 5.5 \\
\hline Chinese & 25.7 \\
\hline
\end{tabular}


Table 6: UK domiciled students achieving a first class or second class upper honours degree (2018/2019) in the $U K^{14}$

\begin{tabular}{|l|r|}
\hline & $\begin{array}{r}\text { First class/ } \\
\text { second upper }\end{array}$ \\
\hline White & 81.4 \\
\hline Mixed & 76.6 \\
\hline Asian & 70 \\
\hline Black & 58.8 \\
\hline Chinese & 76.9 \\
\hline
\end{tabular}
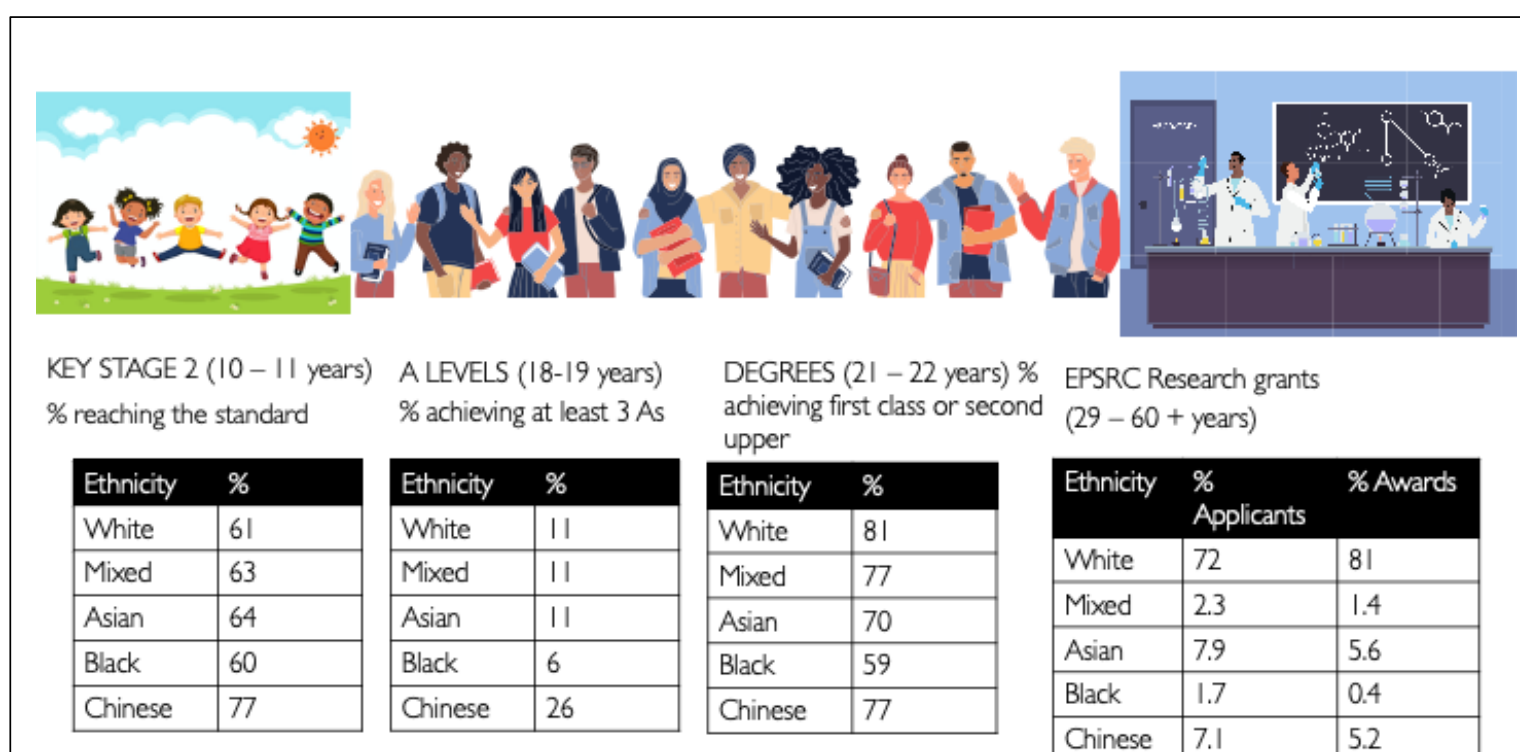

KEY STAGE 2 (10 - I I years)
\% reaching the standard
\begin{tabular}{|l|l|}
\hline Ethnicity $\%$ \\
\hline White & 61 \\
\hline Mixed & 63 \\
\hline Asian & 64 \\
\hline Black & 60 \\
\hline Chinese & 77 \\
\hline
\end{tabular}

\begin{tabular}{|l|l|}
\hline Ethnicity & $\%$ \\
\hline White & 11 \\
\hline Mixed & 11 \\
\hline Asian & 11 \\
\hline Black & 6 \\
\hline Chinese & 26 \\
\hline
\end{tabular}

EPSRC Research grants (29-60+ years)

\begin{tabular}{|l|l|l|}
\hline Ethnicity & \multicolumn{1}{l}{$\%$} \\
\multicolumn{3}{|l|}{ Applicants } \\
\hline White & 72 & 8 Awards \\
\hline Mixed & 2.3 & 1.4 \\
\hline Asian & 7.9 & 5.6 \\
\hline Black & 1.7 & 0.4 \\
\hline Chinese & 7.1 & 5.2 \\
\hline
\end{tabular}

The UK ethnicity award gap

Figure 1: The UK ethnicity award gap. Black students fall behind from the A level assessment period and Chinese students lose their lead at degree level assessments. 
An examination of English educational award data reveals that when pupils are first tested at 7 years old in Key Stage 1 assessments, pupils of all ethnicities are performing at a similar level, with Chinese pupils having a slightly better performance in mathematics in some years (Table 3 ). When pupils are examined at 11 years old in Key Stage 2 assessments, two things are noticeable: Chinese pupils have pulled further ahead in reading, writing and mathematics, but all other pupils are performing at a similar level (Table 4). If any of these pupils wish to achieve a career in science, admission to a research intensive university is a good first step and to secure such a place in the UK, at least 3 A level A grades are usually required. It is by this metric that it becomes clear that the UK education system is spectacularly failing Black pupils (Table 5). At A level, Chinese pupils outperform all other groups and so the lead gained at Key Stage 2 is maintained and strengthened (Table 5). Looking further ahead, by the time our bright young graduates have completed a $3-4$ year degree the difference in awards among the groups is clear. White students are now performing best and the Chinese students have lost the lead gained at Key Stage 2. Asian students have fallen behind and the Black students are now well and truly behind (Table 6). The data reveals that UK universities are not adding value to ethnic minority students. Furthermore, this low award culture persists against a backdrop of ethnic minority students being over represented in UK universities, as they made up $24 \%$ of UK domiciled students in $2018 / 2019^{15}$, well in excess of the proportion of ethnic minorities in the general population $(13 \%)^{10}$. One could argue that maintaining a system that results in low awards to the fastest growing group of higher education consumers does not make good business sense.

Despite the adverse degree outcomes (Table 6), ethnic minority students still hope for science careers, as $50 \%$ of ethnic minority students participated in undergraduate science degrees compared to $48 \%$ of White students in $2018 / 2019^{16}$ and $18 \%$ of $\mathrm{PhD}$ students were from ethnic minority backgrounds in $2018 / 2019^{17}$. However only $9 \%$ of recipients of UKRI studentships were ethnic minorities in $2018 / 2019^{18}$ (note $29 \%$ of UKRI studentship holders withheld their ethnicity data). There is clearly an appetite among UK ethnic minority students to contribute to the creation of scientific knowledge, despite having to work within a culture that systematically results in lower degree classification awards and a lower chance of state financial support. 
What happens when ethnic minority students do attain a science career and begin to compete for grants in order to create scientific advances? Even though the proportion UKRI applicants that are ethnic minorities has risen over the last 5 years, UKRI ethnic minority applicants are more likely to score lower value awards and achieve lower award rates (apart from in fellowships where ethnic minority award rates exceeded White award rates) ${ }^{18}$. As UKRI data also includes data from the arts, humanities and social sciences, it is important to examine what happens in the sciences. As stated above, ethnic minority applicants to the MRC and EPSRC are less likely to be funded when compared to White applicants (Tables 1 and 2) 2,

The low ethnic minority grant award success rate, when compared to White applicants, is matched by the low level of participation of ethnic minorities in the grant prioritization panels, either as panellists or crucially as panel chairs (Table 7), despite being well represented in the peer review college ${ }^{19}$. Panel chairs serve an important role, especially when moderating panel discussions in order to arrive at a collective decision.

Table 7: EPSRC grant reviewers by ethnicity in 2018/2019 $9^{19}$

\begin{tabular}{|l|l|l|l|l|}
\hline Ethnicity & $\begin{array}{l}\text { Reviewer pool }- \\
\text { EPSRC peer } \\
\text { review college }\end{array}$ & $\begin{array}{l}\text { Reviewers } \\
\text { submitting useable } \\
\text { reviews }\end{array}$ & $\begin{array}{l}\text { Grant } \\
\text { prioritisation panel }\end{array}$ & $\begin{array}{l}\text { Grant } \\
\text { prioritisation panel } \\
\text { chair }\end{array}$ \\
\hline White & 77 & 75 & 74 & 80 \\
\hline $\begin{array}{l}\text { Black, Asian or } \\
\text { minority ethnic }\end{array}$ & 15 & 18 & 8 & 4 \\
\hline Not disclosed & 8 & 7 & 18 & 15 \\
\hline
\end{tabular}

It is clear (Figure 1), that being an ethnic minority makes it harder to achieve a successful scientific career and there are differential ethnicity-related outcomes in our education system that contribute to this difficulty. These differential outcomes frustrate ambition and limit the numbers of ethnic minorities that are working at the top of their fields as scientists. In the UK in $2018 / 2019,9 \%$ of White academics 
working in science, engineering and technology subjects were professors whereas the comparative number for ethnic minorities is just $3.2 \%{ }^{20}$.

Where does the problem start? Most children (Black, Mixed, Asian and White) are similar at Key Stage 2 (Figure 1), although Chinese pupils are ahead. For Chinese and Asian students the differential occurs during the undergraduate years, whereas for Black students the differential outcomes occur much earlier, at secondary school.

\section{What can be done.}

If the UK is to fully benefit from its entire population and produce research which serves UK and global communities, it is important to ensure that more ethnic minorities are able to achieve scientific careers. A race equality strategy is required for all aspects of our education sector and the following recommendations are a good place to start.

1. Schools, colleges and universities should be offered financial incentives to assist with closing the awarding gaps between Black and White pupils.

2. Previously the National Institute for Health Research (NIHR) had stated that being in receipt of the Athena Swan kitemark for gender equality was necessary for the award of certain grants (decision now reversed). The original decision resulted in more women researchers being funded by the NIHR ${ }^{21}$. UKRI should consider making large infrastructure grants only to institutions in England that hold a Race Equality Charter Bronze award.

3. All research funders in the UK should examine their peer review processes to ensure ethnic minority researchers are well represented through all stages of the peer review process, including as grant prioritisation panel chairs and members of their governing bodies.

4. Data on the ethnic award gap in schools, colleges and universities, the ethnic research funding gap and the ethnic pay gap in universities should be published annually in a rank ordered list to allow prospective pupils, students and grant applicants to easily access this information. 


\section{Conclusions}

There is a clear deficit in our entire education system that results in ethnic minority pupils being less likely to graduate with a good degree; even though ethnic minority individuals are more likely to opt for a university education when compared to White pupils. Despite good participation in science and engineering disciplines within our universities by ethnic minorities, it is harder for ethnic minority researchers to obtain research funding. This needs to change if the UK is to produce research that benefits the entire population. A number of recommendations have been put forward.

\section{References}

1 Aldridge, R. W. et al. Black, Asian and Minority Ethnic groups in England are at increased risk of death from COVID-19: indirect standardisation of NHS mortality data. Wellcome Open Res 5, 88, doi:10.12688/wellcomeopenres.15922.2 (2020).

2 MRC. Success rates. https://mrc.ukri.org/research/funded-research/success-rates/\#grant (2019).

3 EPSRC. Collecting and analysing diversity data. https:/lepsrc.ukri.org/funding/edi-atepsrc/collecting-and-analysing-diversity-data/ (2018).

4 Adams, J. Collaborations: The fourth age of research. Nature 497, 557-560, doi:10.1038/497557a (2013).

5 AlShebli, B. K., Rahwan, T. \& Woon, W. L. The preeminence of ethnic diversity in scientific collaboration. Nat Commun 9, 5163, doi:10.1038/s41467-018-07634-8 (2018).

6 McKinsey and Co. Diversity Wins. https://www.mckinsey.com/ /media/McKinsey/Featured\%20Insights/Diversity\%20and\%20Inclusion/ Diversity\%20wins\%20How\%20inclusion\%20matters/Diversity-wins-How-inclusion-matters- $v$ F. pdf (2020).

7 Nathan, M. \& Lee, N. Cultural Diversity, Innovation, and Entrepreneurship: Firm-level Evidence from London. Econ Geogr 89, 367-394, doi:10.1111/ecge.12016 (2013).

8 Levine, S. S. et al. Ethnic diversity deflates price bubbles. Proc Natl Acad Sci U S A 111, 18524-18529, doi:10.1073/pnas.1407301111 (2014).

9 Sommers, S. R. On racial diversity and group decision making: Identifying multiple effects of racial composition on jury deliberations. J Pers Soc Psychol 90, 597-612, doi:10.1037/00223514.90.4.597 (2006).

10 Office for National Statistics. 2011 Census: Key Statistics and Quick Statistics for Local Authorities in the United Kingdom. https://www.ons.gov.uk/peoplepopulationandcommunity/populationandmigration/populationestimates /bulletins/keystatisticsandquickstatisticsforlocalauthoritiesintheunitedkingdom/2013-10-11\#ethnicityand-country-of-birth (2011).

11 Government Digital Service. Statistics - Key Stage 1. https://www.gov.uk/government/collections/statistics-key-stage-1 (2019).

12 Government Digital Service. Statistics: Key

https://www.gov.uk/government/collections/statistics-key-stage-2 (2019). 
13 Race Disparity Unit. Students getting 3 A grades or better at A level. https://www.ethnicityfacts-figures.service.gov.uk/education-skills-and-training/a-levels-apprenticeships-furthereducation/students-aged-16-to-18-achieving-3-a-grades-or-better-at-a-level/latest (2020).

14 Advance HE. Equality+ higher education student statistical report. https://www.advancehe.ac.uk/knowledge-hub/equality-higher-education-statistical-report-2020 (2020).

15 HESA. Higher Education Student Statistics: UK, 2018/19 - Student numbers and characteristics.

statistics/numbers (2020).

16 HESA. What do HE students study? https://www.hesa.ac.uk/data-and-analysis/students/whatstudy (2020).

17 HESA. What do HE students study? Personal characteristics. https://www.hesa.ac.uk/data-andanalysis/students/what-study/characteristics (2020).

18 UKRI. Diversity results for UKRI funding data 2014-15 to 2018-19. https://www.ukri.org/wpcontent/uploads/2020/10/UKRI-020920-DiversityResultsForUKRIFundingData2014-19.pdf (2020).

19 EPSRC. EPSRC diversity data on peer review April 2019. https:/lepsrc.ukri.org/files/funding/edi/epsrc-peer-review-diversity-data-narrative-and-tables-april2019-pdff (2019).

20 Advance HE, Equality+ higher education staff statistical report. https://s3.eu-west2.amazonaws.com/assets.creode.advancehe-document-manager/documents/advancehe/058 2020 AdvHE\%20stats report staff FINAL 10mb 1603451440.pdf? X-Amz-ContentSha256=UNSIGNED-PAYLOAD\&X-Amz-Algorithm =AWS4-HMAC-SHA256\&X-AmzCredential =AKIATYAYEYO3HUY745WI\%2F20201217\%2Feu-west-2\%2Fs $3 \% 2 \mathrm{Faws} 4$ request \& $X$ Amz-Date $=20201217 T 142339 Z \& X$-Amz-SignedHeaders $=$ host \& X-Amz-Expires $=604800 \& X$-AmzSignature $=29 b 869 \mathrm{~d} 14 a a f 1 c 5253224988 \mathrm{ea} 7 \mathrm{~d} 33 \mathrm{f4} 3984397766 \mathrm{~b} 56 \mathrm{eld} 95 \mathrm{a} 3 \mathrm{e} 717 \mathrm{ce} 2 \mathrm{fc} 3 \mathrm{f4}$ (2020).

21 Ovseiko, P. V. et al. Effect of Athena SWAN funding incentives on women's research leadership. BMJ 371, m3975, doi:10.1136/bmj.m3975 (2020). 